\title{
THE EASE OF DOING BUSINESS AND STANDARDS OF BUSINESS OPERATIONS OF KINFRA INDUSTRIAL PARKS IN KERALA
}

\author{
Dr. P. Noufal \\ Head, Research Department of Economics, Government College, Kodanchery-673580, \\ Kozhikode District, Kerala, India.
}

\begin{abstract}
Industrial parks are receiving increasing attention in the sustainability discourse and its basic mandate is to nurture appropriate industries along with expanding the industrial base of the economy with global standards in quality, technology and management. As an innovative industrial initiative, the establishment of KINFRA industrial parks attempts to explore an ecosystem where productive and innovative entrepreneurship germinates, sustains and grows leading to the creation of a more vibrant and dynamic industrial economy in Kerala. Within 25 years of functioning, KINFRA has ventured many industrial parks in the fast growing core competency sectors and at their best, these industrial parks align the infrastructure provision and agglomeration economies to jolt the industrial growth of the State. It is in the context, the paper attempts to explore the economic imperative and operational efficiency of KINFRA industrial parks in terms of the 'ease of doing' and 'standards of business operations' indices.
\end{abstract}

KEYWORDS: Kerala Industry, Industrial Promotion, KINFRA, Industrial Parks, Ease of Doing Business, Standards of Business Operations.

\subsection{INTRODUCTION}

The Kerala Industrial Infrastructure Development Corporation, popularly known as KINFRA, is a statutory body set up by an Act of State Legislature in February, 1993. It stands as a flagship of Kerala's industrial fleet as it ventures into the high seas of global commerce. Being the industrial catalyst of the State, KINFRA promotes the concept of 'industrial parks' in Kerala. Its vision is to create a State where industry thrives in the midst of the rich green environs and where people flourish in an achievement that fosters growth and the freedom to innovate. Its mission is to enable development across the State by identifying and promoting core competency industries of each region, creating walkin and manufacture environments and wooing discerning investors from across the world. It has catered to the industry-specific infrastructure requirements of the State by creating walk-in and manufacture environments in ready-to-use 'industrial complexes' that provide all the facilities required in the starting and nurturing of an industry. As the industrial facilitator of Kerala, KINFRA has completed 25 years of its operation and is having 22 fully operational parks, 7 premier ongoing projects and about 9 major projects on anvil at present. The ambience and flawless infrastructure facilities available in the industrial parks aim to provide a typical business or entrepreneurial culture in the State for the development of a high-tech, non-polluting and export-oriented industries and thereby create topnotch 'industrial spots' or 'industrial townships' in Kerala.

\subsection{RESEARCH PROBLEM}

The low level of industrial development in the backward regions of Kerala is one of the major developmental issues confronting the State today. 


\section{EPRA International Journal of Research and Development (IJRD)}

Development of adequate and commendable infrastructure is an essential pre-requisite for rapid industrialisation and the inadequacy of appropriate infrastructure is a major factor hindering the industrial development of the backward regions of the State. Industrial parks can develop certain synergies and a typical entrepreneurial culture in the industrial economy of any country in terms of excellent institutional framework, support services and physical infrastructure and are aptly treated as policy drivers to foster sufficing investments, employment, competitiveness, sustainable business strategies and regional economic development. Thus, it becomes significant to examine the economic imperative of KINFRA industrial parks with particular reference to the 'ease of doing business' and 'standards of business operation' indices.

\subsection{OBJECTIVES OF THE STUDY}

By pioneering the concept of 'industrial parks', KINFRA provides an ambience for the enterprise and innovation to flourish and thereby profoundly influence the industrial economy of Kerala. KINFRA unleashes the industrial potential of the State and thereby enables its progressive and sustainable industrial development. In the context, the study attempts two major objectives, namely: (i) to examine the extent of 'ease of doing business' as envisaged by KINFRA industrial parks in Kerala and (ii) to explore the 'standards of business operations' as provided by KINFRA industrial parks on the industrial economy of the State.

\subsection{HYPOTHESES \& TEST(s)}

Within the last 25 years of its operation, KINFRA is busy with a mission to make Kerala the most favoured destination for competitive industrial development with the provision of commendable infrastructure and support services. Within the framework of the research objective, the study attempts to test two hypotheses as: (i) the operational efficiency of KINFRA industrial parks in terms of the 'ease of doing business' is nugatory and (ii) the operational efficiency of KINFRA industrial parks in terms of its 'standards of operations' is also nugatory. The hypotheses are being tested by using Wilcoxon Signed Rank Test, based on the 'median' value of the data collected.

\subsection{METHODOLOGY}

KINFRA has completed 25 years of its operation in Kerala. The study takes into account only a decennial period of its operation, that is, from 2003 to 2015 for exploration and analysis. There are a total of 22 fully operational industrial parks set up by KINFRA as on $31^{\text {st }}$ March, 2019. The study takes into account only the case of those industrial parks which have been set up before the year 2010. So the total number of sample is 18 fully operational parks out of a total of 22 . The study uses both primary and secondary data. Data have been collected and arranged by using a 5point likert scale as shown below:

\begin{tabular}{|c|c|c|}
\hline Scale Value & Choice of Evaluation & Standard Score \\
\hline 1 & Completely Agree & 100 \\
\hline 2 & Mostly Agree & 75 \\
\hline 3 & Neither Agree Nor Disagree & 50 \\
\hline 4 & Mostly Disagree & 25 \\
\hline 5 & Completely Disagree & 00 \\
\hline
\end{tabular}

\subsection{ANALYSIS OF EASE OF DOING BUSINESS}

Ease of doing business is one among the parameters selected for measuring the operational efficiency of KINFRA industrial parks. KINFRA plays a pivotal role as the industrial catalyst of the State and as such, it provides a conducive environment for the existing industries to consolidate and new industries to come up. By enabling growth and a typical entrepreneurial as well as business culture, KINFRA industrial parks assure quality standards and a congenial ambience for the easy starting and sustainable growth of industries in the
State. Thus, it becomes imperative to explore the viability of the business environment provided by KINFRA with respect to the 'ease of doing business' which is presumed as a composite index having certain parameters addressing the operational effectiveness of KINFRA.

\subsubsection{Ease of Doing Business - Aspects for Evaluation}

The major aspects for evaluating the 'ease of doing business' as provided by the KINFRA industrial parks in Kerala are given below: 
EPRA International Journal of Research and Development (IJRD)

\begin{tabular}{|c|l|}
\hline Parameters & \multicolumn{1}{c|}{ Description } \\
\hline 1 & Affordable premium and better lease out period. \\
\hline 2 & Flexible terms and conditions for the entrepreneurs. \\
\hline 3 & Excellent infrastructure and other support services. \\
\hline 4 & Excellent common facilities for smooth business. \\
\hline 5 & Well organised and hassle free business environment. \\
\hline 6 & Consistent and continuous communication of the key initiatives. \\
\hline
\end{tabular}

1.6.2. Ease of Doing Business Operational Efficiency
The responses on the major aspects of evaluation of 'ease of doing business' of KINFRA industrial parks in Kerala are given below:

\begin{tabular}{|c|c|c|c|c|c|c|c|}
\hline \multirow{2}{*}{$\begin{array}{l}\text { Evaluation } \\
\text { Parameters }\end{array}$} & \multicolumn{5}{|c|}{ Scale and Proportion } & \multicolumn{2}{|c|}{ Majority } \\
\hline & 1 & 2 & 3 & 4 & 5 & Response & Per Cent \\
\hline \multirow{2}{*}{ Parameter-1 } & 06 & 12 & 00 & 00 & 00 & \multirow{2}{*}{$\begin{array}{l}\text { Mostly } \\
\text { Agree }\end{array}$} & \multirow{2}{*}{66.7} \\
\hline & $(33.3)$ & $(66.7)$ & -- & -- & -- & & \\
\hline \multirow{2}{*}{ Parameter-2 } & 07 & 11 & 00 & 00 & 00 & \multirow{2}{*}{$\begin{array}{l}\text { Mostly } \\
\text { Agree }\end{array}$} & \multirow{2}{*}{61.1} \\
\hline & $(38.9)$ & $(61.1)$ & -- & -- & -- & & \\
\hline \multirow{2}{*}{ Parameter-3 } & 12 & 06 & 00 & 00 & 00 & \multirow{2}{*}{ Completely Agree } & \multirow{2}{*}{66.7} \\
\hline & $(66.7)$ & $(33.3)$ & -- & -- & -- & & \\
\hline \multirow{2}{*}{ Parameter-4 } & 05 & 10 & 03 & 00 & 00 & \multirow{2}{*}{$\begin{array}{l}\text { Mostly } \\
\text { Agree }\end{array}$} & \multirow{2}{*}{55.5} \\
\hline & $(27.8)$ & $(55.5)$ & $(16.7)$ & -- & -- & & \\
\hline \multirow{2}{*}{ Parameter-5 } & 06 & 11 & 01 & 00 & 00 & \multirow{2}{*}{$\begin{array}{l}\text { Mostly } \\
\text { Agree }\end{array}$} & \multirow{2}{*}{61.1} \\
\hline & (33.3) & $(61.1)$ & $(05.6)$ & -- & -- & & \\
\hline \multirow{2}{*}{ Parameter- 6} & 04 & 12 & 02 & 00 & 00 & \multirow{2}{*}{$\begin{array}{l}\text { Mostly } \\
\text { Agree }\end{array}$} & \multirow{2}{*}{66.7} \\
\hline & $(22.2)$ & $(66.7)$ & (11.1) & -- & -- & & \\
\hline
\end{tabular}

Source: Survey Research.

1.6.3. Ease of Doing Business Statistical Testing \& Interpretation:
The major aspects and responses on the 'ease of doing business' of KINFRA industrial parks in Kerala are given below:

\begin{tabular}{|l|l|}
\hline $\mathbf{H}_{\mathbf{0}}$ & $\begin{array}{l}\text { The operational efficiency of KINFRA industrial parks in terms of "ease } \\
\text { of doing business" is nugatory. }\end{array}$ \\
\hline Test & Wilcoxon Signed Rank (Median) Test \\
\hline Hypothetical Median & 3 \\
\hline P-value & $6.699-5$ \\
\hline Observed Median & 2 (True location is less than 3$)$ \\
\hline Decision & $\begin{array}{l}\text { Reject the null hypothesis }\left(\mathrm{H}_{0}\right) \text { and accept the alternative hypothesis } \\
\left(\mathrm{H}_{1}\right) .\end{array}$ \\
\hline $\mathbf{H}_{\mathbf{1}}$ & $\begin{array}{l}\text { The operational efficiency of KINFRA industrial parks in terms of "ease } \\
\text { of doing business" is 'mostly effective.' }\end{array}$ \\
\hline
\end{tabular}


The responses on each of the select parameters of the criteria 'ease of doing business' is analysed and the status of operational efficiency in terms of the chosen parameters is recorded with corresponding scores. Having been set the null hypothesis as 'the operational performance of KINFRA industrial parks in terms of "ease of doing business" is nugatory', the study uses Wilcoxon Signed Rank Test for testing the hypothesis. Assuming a hypothetical median value of 3 in a 5point likert scale, the observed median is 2 with a $\mathrm{P}$ value of $6.699^{-5}$. The null hypothesis is therefore rejected and the study accepts the alternative hypothesis, signifying the operational performance of KINFRA industrial parks in terms of the parameter 'ease of doing business' is mostly effective.

\subsection{ANALYSIS OF STANDARDS OF BUSINESS OPERATIONS}

Most businesses experience some operational issues that can be resolved with the identification of certain best practices called the standards of business operations. Being the industrial facilitator of the State, KINFRA generally follows some standard ways of doing things complying with the requirements of its stakeholders. It aims at producing superior results with its strategic planning and best practice methods. KINFRA always attempts to make both quantitative and qualitative improvements in the industry-specific infrastructure requirements of the State, by complying certain benchmarks and standards of operations. By stimulating diverse avenues of business, KINFRA drives the direction and pace of innovation that underpins the future industrial growth of the State. The industrial parks set up by KINFRA are actually the innovation hubs of the State for its diverse and dynamic industrial development. Keeping strict adherence to quality and other standards of operations, KINFRA took the lead in promoting a typical business or entrepreneurial culture in Kerala. The study presumes 'standards of business operations' as a composite index having certain aspects which can be used to obtain some basic reflections on the operational efficiency of KINFRA.

\subsubsection{Standards of Business Operations} - Aspects for Evaluation:

The major aspects for evaluating the 'standards of business operations' as provided by the KINFRA industrial parks in Kerala are given below:

\begin{tabular}{|c|l|}
\hline Parameters & \multicolumn{1}{c|}{ Description } \\
\hline 1 & Excellent business environment at affordable cost and time span. \\
\hline 2 & Fullest utilisation of the capacity of industrial units. \\
\hline 3 & Optimum use of resources and technology for the industrial units. \\
\hline 4 & Support to the entrepreneurs to manage their operating risk. \\
\hline 5 & Promotional activities for the betterment of industrial units. \\
\hline 6 & Support to deliver high standards of quality in businesses. \\
\hline
\end{tabular}

1.7.2. Standards of Business Operations - Operational Efficiency
The responses on the major aspects of evaluation of 'standards of business operations' of KINFRA industrial parks in Kerala are given below:

\begin{tabular}{|c|c|c|c|c|c|c|c|}
\hline \multirow{2}{*}{$\begin{array}{l}\text { Evaluation } \\
\text { Parameters }\end{array}$} & \multicolumn{5}{|c|}{ Scale and Proportion } & \multicolumn{2}{|c|}{ Majority } \\
\hline & 1 & 2 & 3 & 4 & 5 & Response & Per Cent \\
\hline \multirow{2}{*}{ Parameter-1 } & 11 & 07 & 00 & 00 & 00 & \multirow{2}{*}{$\begin{array}{c}\text { Completely } \\
\text { Agree }\end{array}$} & \multirow{2}{*}{61.1} \\
\hline & $(61.1)$ & $(38.9)$ & -- & -- & -- & & \\
\hline \multirow{2}{*}{ Parameter-2 } & 05 & 10 & 03 & 00 & 00 & \multirow{2}{*}{$\begin{array}{l}\text { Mostly } \\
\text { Agree }\end{array}$} & \multirow{2}{*}{55.6} \\
\hline & $(27.7)$ & $(55.6)$ & $(16.7)$ & -- & -- & & \\
\hline \multirow{2}{*}{ Parameter-3 } & 04 & 12 & 02 & 00 & 00 & \multirow{2}{*}{$\begin{array}{l}\text { Mostly } \\
\text { Agree }\end{array}$} & \multirow{2}{*}{66.7} \\
\hline & $(22.2)$ & $(66.7)$ & (11.1) & -- & -- & & \\
\hline Parameter-4 & 00 & 04 & 04 & 10 & 00 & Mostly & 55.6 \\
\hline
\end{tabular}


EPRA International Journal of Research and Development (IJRD)

Volume: 6 | Issue: 2 | February 2021

- Peer Reviewed Journal

\begin{tabular}{|c|c|c|c|c|c|c|c|}
\hline & -- & $(22.2)$ & $(22.2)$ & $(55.6)$ & -- & Disagree & \\
\hline \multirow{3}{*}{ Parameter-5 } & 11 & 07 & 00 & 00 & 00 & \multirow{2}{*}{$\begin{array}{c}\text { Completely } \\
\text { Agree }\end{array}$} & \multirow{2}{*}{61.1} \\
\cline { 2 - 6 } & $(61.1)$ & $(38.9)$ & -- & -- & -- & $\begin{array}{c}\text { Mostly } \\
\text { Agree }\end{array}$ & \multirow{2}{*}{66.7} \\
\hline \multirow{2}{*}{ Parameter-6 } & 06 & 12 & 00 & 00 & 00 & -- & \multicolumn{2}{|c|}{} \\
\cline { 2 - 7 } & $(33.3)$ & $(66.7)$ & -- & -- & - &
\end{tabular}

Source: Survey Research.

1.7.3. Standards of Business Operations Statistical Testing \& Interpretation
The major aspects and responses on the 'standards of business operations' of KINFRA industrial parks in Kerala are given below:

\begin{tabular}{|c|c|}
\hline $\mathbf{H}_{\mathbf{0}}$ & $\begin{array}{l}\text { The operational efficiency of KINFRA industrial parks in terms of } \\
\text { "standards of business operations" is nugatory. }\end{array}$ \\
\hline Test & Wilcoxon Signed Rank Test \\
\hline Hypothetical Median & 3 \\
\hline P-value & $5.339-5$ \\
\hline Observed Median & 2 (True location is less than 3 ) \\
\hline Decision & $\begin{array}{l}\text { Reject the null hypothesis }\left(\mathrm{H}_{0}\right) \text { and accept the alternative hypothesis } \\
\left(\mathrm{H}_{1}\right) \text {. }\end{array}$ \\
\hline $\mathbf{H}_{1}$ & $\begin{array}{l}\text { The operational efficiency of KINFRA industrial parks in terms of } \\
\text { "standards of business operations" is 'mostly effective.' }\end{array}$ \\
\hline
\end{tabular}

The responses on each of the select parameters of the criteria 'ease of doing business' is analysed and the status of operational efficiency in terms of the chosen parameters is recorded with corresponding scores. Having been set the null hypothesis as 'the operational performance of KINFRA industrial parks in terms of "ease of doing business" is nugatory', the study uses Wilcoxon Signed Rank Test for testing the hypothesis. Assuming a hypothetical median value of 3 in a 5point likert scale, the observed median is 2 with a $\mathrm{P}$ value of $6.699^{-5}$. The null hypothesis is therefore rejected and the study accepts the alternative hypothesis, signifying the operational performance of KINFRA industrial parks in terms of the parameter 'ease of doing business' is mostly effective.

\subsection{CONCLUSION}

Being the industrial catalyst of the State, KINFRA facilitates the setting up and management of theme-based industrial parks so as to modernise and diversify the industrial economy of Kerala. The infrastructure and support services offered by KINFRA industrial parks attract entrepreneurs from across the world to the industrial landscape of Kerala and have positively contributed to its industrial development. KINFRA industrial parks are beneficial in the fact that they apply modern technologies and innovations, bring economic and innovative potential or internationally well-proven know-how and thus support the hasty industrial development of the State. As an innovative and promising strategy for the sustainable industrial development of the regional economy, industrial parks integrate business success, environmental excellence and community connections with certain cascading effects on the regional industrial economy. The operational performance and efficacy of KINFRA industrial parks in terms of the 'ease of doing business' and 'standards of business operation' indices ratify the fact.

\section{SELECT REFERENCE}

1. Government of Kerala. (2020). Economic Review 2019. Thiruvananthapuram: Kerala State Planning Board.

2. ---- (2019). The Kerala Industrial and Commercial Policy 2018. Thiruvananthapuram: Department of Industries and Commerce.

3. Institute for Studies in Industrial Development (ISID). (2010). SME Clusters in India: Identifying Areas of Intervention for Inclusive Growth. New Delhi: ISID. 
4. Noufal, P. (2020). 'The Present Status and Growth Performance of KINFRA Industrial Parks in Kerala' in Strads Research. 7(8): 95109.

5. ---- (2020). 'Operational Performance of KINFRA Industrial Parks in Kerala: Select Inferences' in EPRA International Journal of Multidisciplinary Research. 6(8): 115-122.

6. ---- (2019). Operational Efficiency of KINFRA Industrial Parks and Its Impact on the Industrial Development of Kerala. Unpublished Ph.D. Thesis. University of Calicut.

7. Saleman, Yannick and Luke Simon Jordan (2013). The Implementation of Industrial Parks-Some Lessons Learned in India. Washington, DC: World Bank.

8. Schwab, Suzanne (2012). A New Class for Industrial Parks. Irvine: Department of Planning, Policy and Design, University of California.

9. United Nations Industrial Development Organisation (UNIDO). (2017). Implementation Handbook for Eco-Industrial Parks. Vienna: UNIDO. 